\title{
MANAGEMENT PLANS AND WEB-GIS SOFTWARE APPLICATIONS AS ACTIVE AND DYNAMIC TOOLS TO CONSERVE AND VALORIZE HISTORIC PUBLIC GARDENS.
}

\author{
A. Cazzani ${ }^{1 *}$, C.M. Zerbi ${ }^{2}$, R. Brumana ${ }^{3}$ \\ ${ }^{1}$ DASTU - Dipartimento di Architettura e Studi Urbani (Department of Architecture and Urban Studies), \\ Politecnico di Milano, Italy - alberta.cazzani@polimi.it \\ ${ }^{2} \mathrm{PhD}$ architect freelance, Studio Lunigiana15, Milan, and DASTU - Dipartimento di Architettura e Studi Urbani \\ (Department of Architecture and Urban Studies), Politecnico di Milano, Italy - c.zerbi@lunigiana15.it \\ ${ }^{3}$ DABC - Dipartimento di Architettura, Ingegneria delle costruzioni e Ambiente costruito (Department of Architecture, \\ Built environment and Construction engineering), Politecnico di Milano, Italy - raffaella.brumana@polimi.it
}

\section{Commission II, WG II/8}

\begin{abstract}
KEY WORDS: Historic Gardens, Historic and Critical Analysis, Survey, Management Plan, GIS Sotfware application, Preservation
\end{abstract} innovative map tools

\begin{abstract}
:
Historic gardens are artefacts that evolve in a continuous and unavoidable way, and, at the same time, they are heritage and cultural sites that need to be conserved: the recognition of this dual nature motivates us to seek for new approaches to their management issues. Whilst it is necessary to follow site mutations and valorize its features while dynamically changes the appearance of the garden and the needs of the society, at the same time it is fundamental that an appropriate strategic plan sets a target for the garden, a mid-long term vision, in order to preserve botanic and documentary value and maintain historic and artistic significance. The paper analyzes historical sources, surveys, thematic maps and interpretations to study historic public gardens, considering complexity and vulnerability of the components and issues involved in historic gardens and consequent multidisciplinary approach. In order to identify conservation and management criteria it underlines analysis and evaluation of the environmental, architectural, landscape and perceptive features of the historic garden and its surroundings, demonstrating the importance to study the site historic stratification and the site context in order to define preservation goals to prevent decay, to mitigate impacts, to set up maintenance programs and management plans. The aim of this essay is also to highlight the role of GIS and WebGIS applications - targeted at public administrations - that integrate the spatial component (topographic map, ortophoto, physical plans, cadastral maps) and databases about botanic inventories and conservation and valorization treatments of historic public of public gardens. ${ }^{1}$
\end{abstract}

\section{INTRODUCTION}

The goal of this paper is to analyse historic gardens formerly privately-owned and now publicly-owned (usually by Municipalities), often in urban or peri-urban areas, characterized by free and largely unregulated access, that frequently present decay problems and lack of maintenance, respectful use and compatible treatments. Many of these sites of cultural importance have lost their identity and are currently considered ordinary and anonymous public green areas.

This paper aims to exam methods to analyse, document and evaluate the complexity of the historic gardens and to explore possible approaches to management and to create public awareness of these sites.

Every intervention considered in both ordinary or extraordinary way, if well-connected to the strategic vision formerly defined, shall support conservation and compatible development of the historic public gardens.
Hence the importance to draft and adopt a programmed Management Plan, an operational tool widely used by institutions with international importance like UNESCO, National Trust (UK) and National Park Service (USA).

An historic public garden Management Plan collects information regarding the complexity of the site and defines intervention strategies aiming at its optimal conservation and valorization.

The final goal of the paper is to analyze the connection between Management Plans and GIS/WebGIS applications currently developed, considering some case studies. Specifically WebGIS applications can manage all information about historic public gardens and their components and features (trees, lawn areas, hedges, trails and water network, technological plants, pavements, etc.) and register and program their maintenance and care, whether lawn cutting jobs, pruning trees, pest control and fertilization, technical inspections on monumental trees.

\footnotetext{
* Corresponding author

${ }^{1}$ The present work was conceived and written jointly by the three authors. In particular, Alberta Cazzani developed section 2, Carlotta Maria Zerbi developed section 3 and Raffaella Brumana developed section 4. The authors collaborated in the writing of Abstract, Introduction and Conclusion, and for the final revision of the manuscript.
} 
These WebGIS applications are particularly popular with municipal administrations because they join tree inventory and historic garden analysis with all processes of organization and decision making, and they offer a guaranteed detailed and upto-date database comprising all elements of public gardens and green areas.

\section{CONSERVATION AND MANAGEMENT PROBLEMS OF HISTORIC PUBLIC GARDENS}

A garden is made predominantly (though not exclusively) by vegetation, in order to satisfy a series of functions: aesthetic, recreational, decorative, of social representativeness, but also productive (of fruits, flowers, vegetable, timber). It is a multifunctional as well as multi-material site that also acquires over time a wealth of meanings that gradually become stratified in it: architectural, botanical, agronomic, cultural, aesthetic, ecological, etc. (Harney, 2014) (Figures 1-2).

The preservation of these meanings is very delicate, both for their complexity, and for the precariousness of the materials that make up the garden: living material, in constant evolution, subjected to decay, strongly dependent on climate and geomorphological conditions (Vv.Aa., 2001).

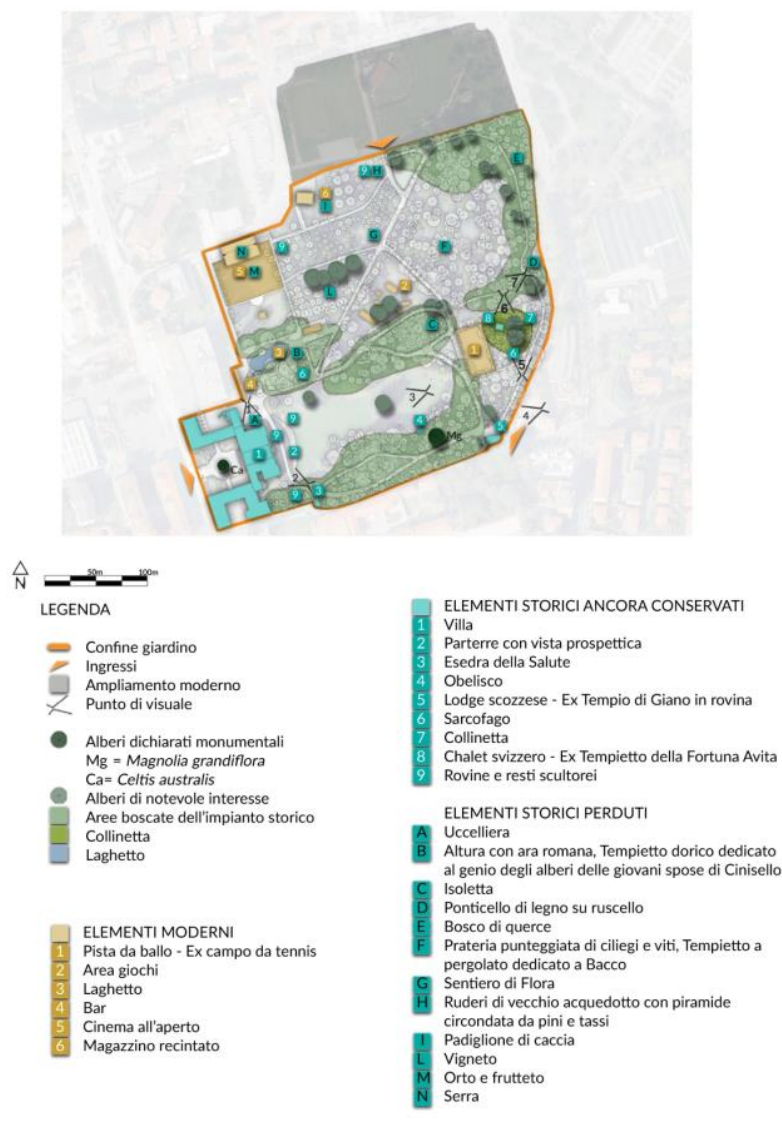

Figure 1. Analysis of historic and modern elements of Villa Ghirlanda Silva historic public garden in Cinisello Balsamo

(Milan Province).

The phase of knowledge and analysis of a historic garden must necessarily be the premise to any conservation or maintenance intervention. In addition to specific historical research (from the analysis of cartography and historical iconography to the examination of documents referring to the property and the garden in particular), it is essential to provide accurate geometric and botanical surveys to understand the current consistency of the site, its vegetal, architectural, perceptive, landscape and naturalistic components (Boriani, Cazzani, 2004) (Figure 3).

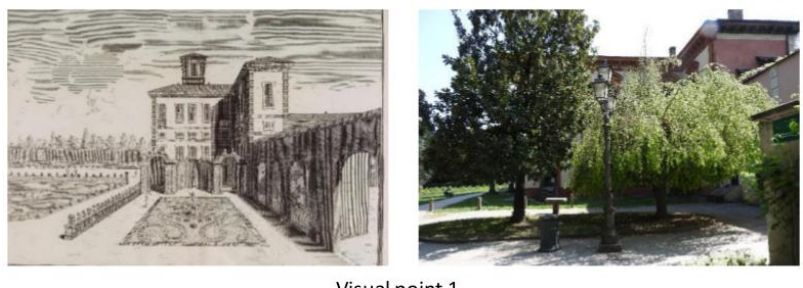

Left: M. Dal Re, Prospetto del Palazzo di Cinisello dalla parte principale, 1726. Right: current picture of the same view for comparison.

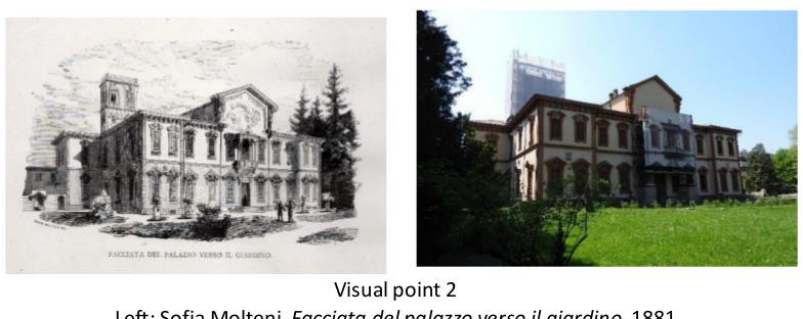

Solteni, Facciata del palazzo verso il giardino, 1881 Right: current picture of the same view for comparison.

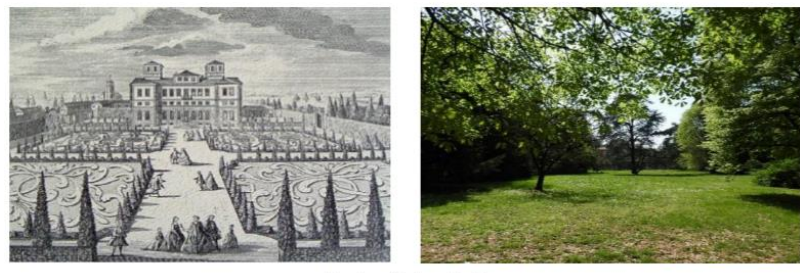

Punto di visuale 3

A sinistra: K. Remshart, La villa e il parterre, acquaforte, ante 1735. Right: current picture of the same view for comparison.

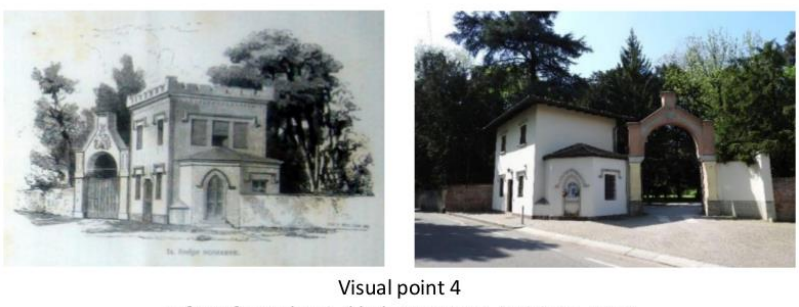

Left: Sofia Molteni, Il lodge scozzese, incisione, 1857 Right: current picture of the same view for comparison.

Figure 2. Comparison between historical images and current pictures of the same views throughout Villa Ghirlanda Silva historic public garden in Cinisello Balsamo (Milan Province).

It is also important to consider the visual and functional relationships that exist between the site and its surroundings: the design of a garden often does not end within the boundaries of the property. The landscape project frequently involved spatially and functionally the surrounding territory (in particular the water supply or disposal network, the tree-lined access roads to the site, the adjacent agricultural system) and favored some visual relationships even of long distance: panoramic views towards mountains, or lakes, vistas towards significant architectures that were incorporated as scenic elements of the architectural composition.

These relationships are often ignored by current planning and design practice: the external perspectives, the water network, the functional and ecological connection with the surrounding landscape and the natural and agricultural environment are largely neglected.

We must also remember that in the historic garden the different 
tree species are not interchangeable with each other, not only for climatic and soil reasons, but also for the landscape and architectural meaning attributed to them: any treatment should be carried out taking into account these aspects to avoid that incorrect plantings, impoverishment of the botanical varieties present on the site, excessive or incorrect pruning, can transform a historic garden into a banal green area.

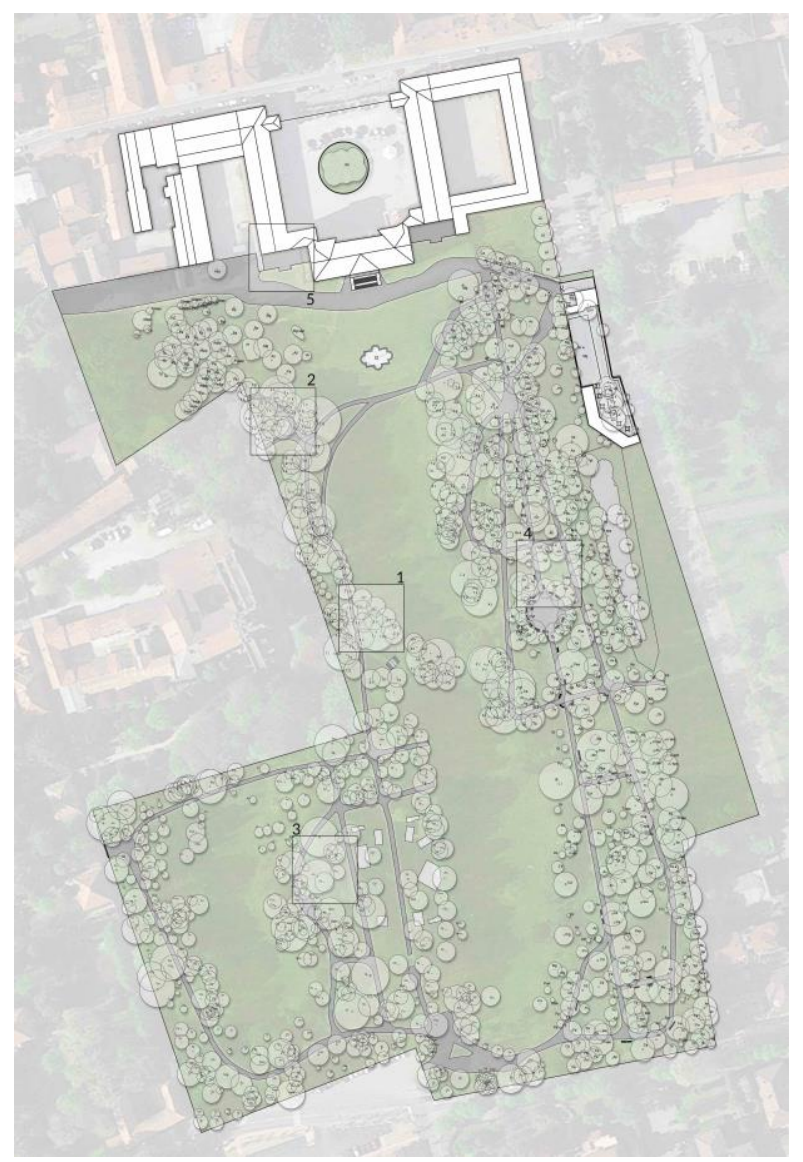

Figure 3. Botanic survey of Villa Cusani Traversi Tittoni historic public garden in Desio (Monza and Brianza Province).

The simplification of maintenance that today characterizes the management of many gardens and the lack of proper supervision are some of the main factors of degradation and alteration of the historic garden settlements.

The frequently identifiable problems are: impoverishment or decay of vegetation, dead plants that are no longer replaced or replaced with others, of different and not compatible species, statues or other historical features moved from their original location or sold or stolen, hidden or altered views (Figure 4).

The transfer of ownership, connected with the request to use historic gardens for the community needs, has frequently led to a use as public green areas, without taking into proper consideration the historical typological characteristics of these sites. The introduction of recreational features (such as, for example, playgrounds, benches, theaters or outdoor cinemas, stages, sport fields) and service facilities (parking lots, lighting systems, toilets, fences, signs, picnic areas, etc.), the spontaneous opening of new paths due to the increment of visitors, the use of lawn parterres as areas for sports activities, the impact on new functions, are just some of the issues that often occurred in parks and historic gardens following the opening to the public.
The main general problem that characterises many historic public gardens is a gradual loss of Identity. The reason for this is that the visitors often do not recognise the gardens as sites of cultural and historical importance at the same level as the connected villas. This is mainly due to the fact that often the characteristics of the gardens changed so much over time that it is difficult to identify their value.
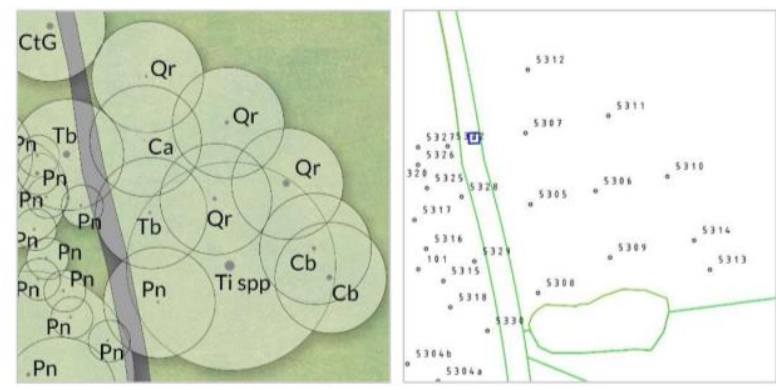

A. The overall survey of existing trees can be obtained by visual inspection and graphic rendering (left) and supplemented with ICT-based geolocation data (right) using R3-Trees software

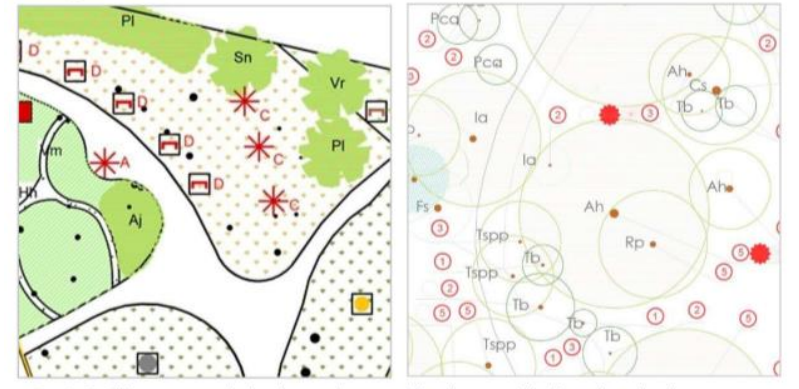

B. Left- The survey of shrubs and ground-level materials lists the shrubs, grasses and herbs, the paving materials, and the constructions, including technical systems and furnishings. Right - The survey of principal botanical aspects lists plants according to blooming characteristics, leaf colours or fruiting, and highlights botanic specimens exceptional for dimensions, species rarity or age

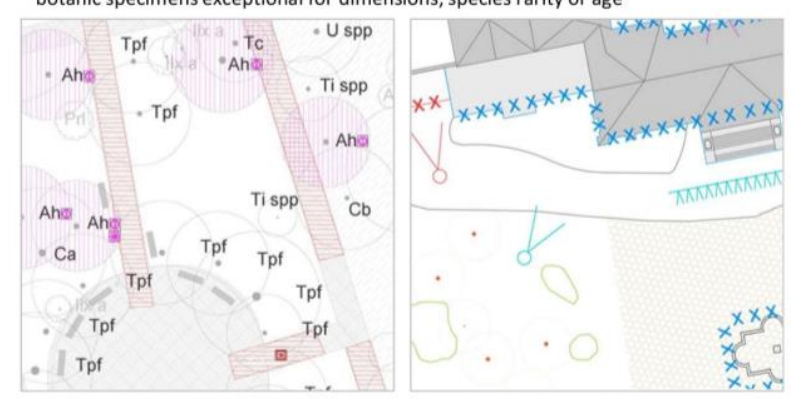

c. Left - A phytopathological survey helps classify, for each tree, the most important plant health issues, the relevant mechanical damages, and possible problems related to insufficient or wrong maintenance practice. Right - The survey of the architectural characters of vegetation includes listings of the principal views across the site, the presere of spcilly significant tree ficant tree groupings, like single monumental trees, or rows or groves, woodland

Figure 4. Extracts from thematic surveys of Villa Cusani Traversi Tittoni historic garden in Desio (Monza and Brianza Province).

In the case of historic gardens open to the public, it is important to think that, in the dense urbanization of today's cities, specific characteristics that distinguish historic gardens from other public green areas are often not recognized and valued. In many cases, historic gardens are considered and treated as standard public green areas, focusing on recreational and social purposes, forgetting the cultural and landscape value.

Historic public gardens should be used not only as recreational spaces, but also as cultural sites, ensuring that any new functions and features added due to social contemporary needs are compatible with the historical, architectural and landscape design. 
It is necessary to consider that an historic garden now public:

- had a private use, now it is public;

- had a compositional layout that is no longer clearly legible;

- had a well-designed relationship with the villa and the context (rural or urban);

- had a wealth of vegetation and architectural elements and more consistent furnishings than the current one;

- had agricultural-productive portions, today almost always disappeared;

- had a continuous maintenance performed by gardeners who knew and monitored the site, while today the maintenance is often entrusted to external firms - more or less specialized in the care of historic gardens - and performed by different operators with very diverse methods;

- offered views and vistas of the surrounding landscape, today often modified or lost.
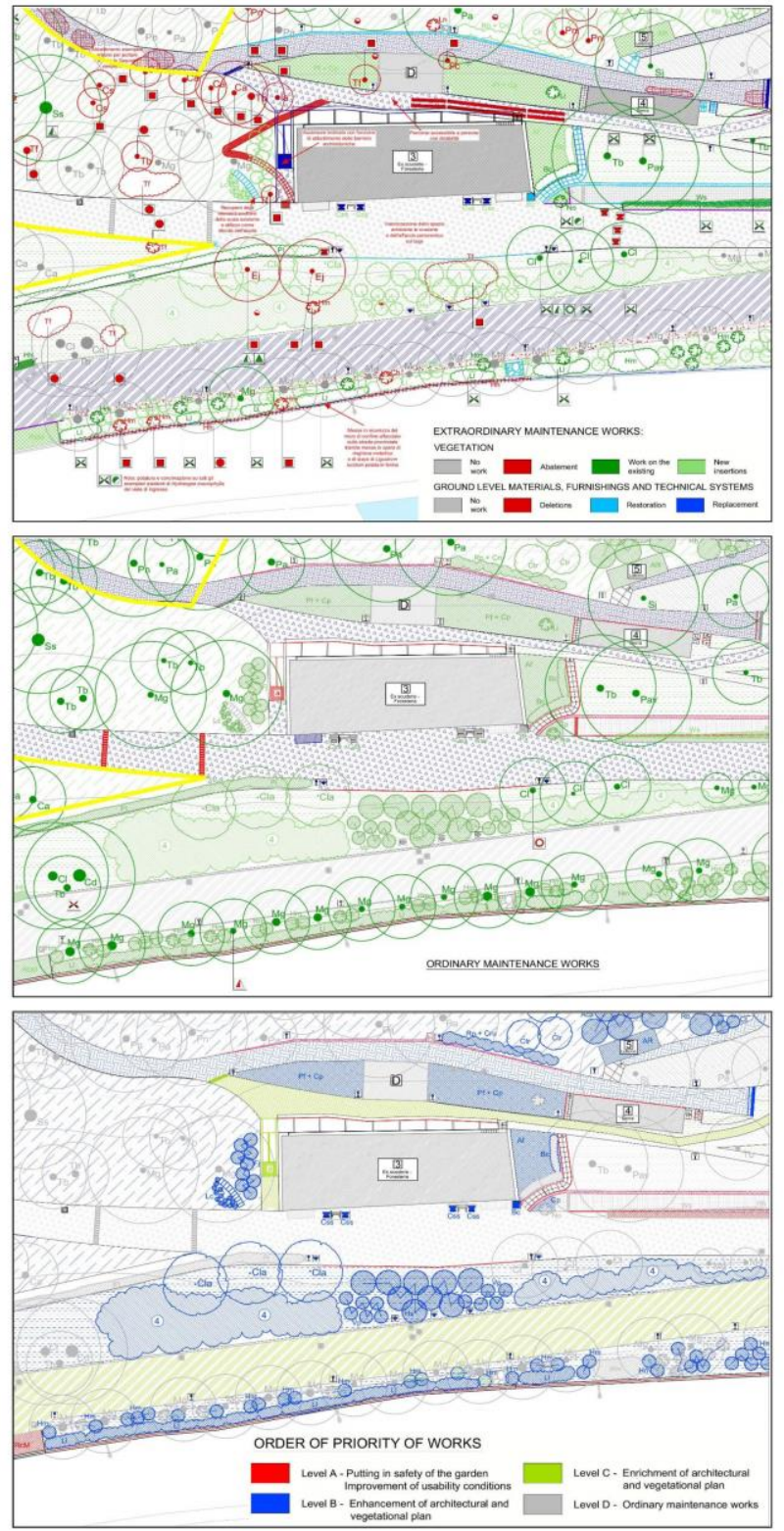

Figure 5. Extraordinary and ordinary maintenance works, and order of priority of works, on the former stables area of the

Villa del Grumello historic garden on Como Lake.

With regard to the maintenance and conservation criteria, it must be considered that the management of an historic public garden must be continuous and planned, but unfortunately the current management of historic public gardens is often assimilated to public green areas, made up of ordinary maintenance treatments and occasional extraordinary works aimed at solving contingent problems (Figures 5-6).

Recognizing cultural and landscape significance is required to develop a medium-long term policy, in order to examine the historic garden as a living, dynamic system - because it is composed mainly of vegetation - to conserve and valorize its stratification and to define a compatible and recognizable reuse project.
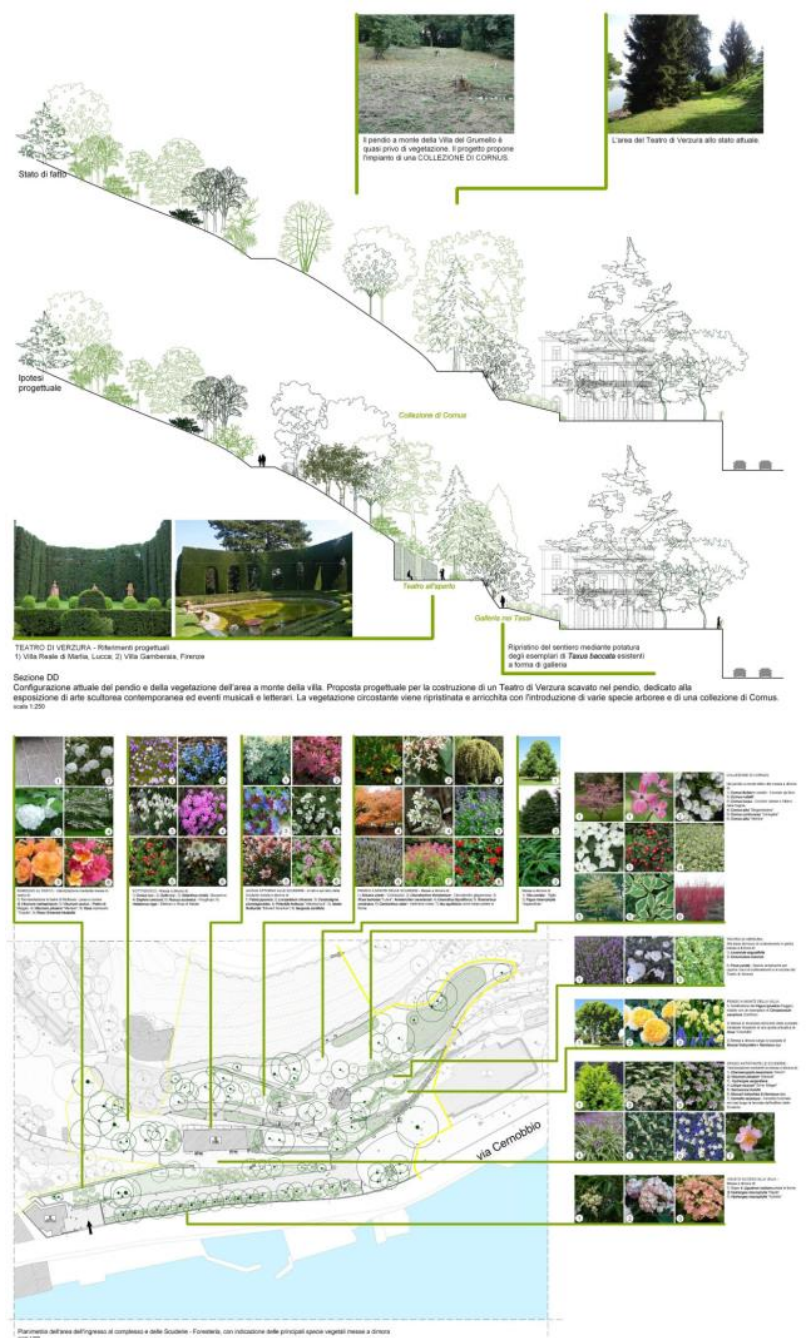

Figure 6. Conservation intervention on the former stables area of the Villa del Grumello historic garden on Como Lake.

\section{HISTORIC GARDEN MANAGEMENT PLAN}

Historic gardens are dynamic artefacts and, at the same time, they are architectural and landscape sites that need to be conserved. For this dual nature, it is fundamental that an appropriate strategic plan set a target for the garden, in order to preserve botanic and documentary value and maintain historic and artistic significance. Every intervention programmed, in both ordinary or extraordinary mode, should be focused on conservation and compatible development of the historic public garden. Hence the importance to draft and adopt a programmed Management Plan, an operational tool widely used by institutions with international importance like UNESCO, National Trust (UK) and National Park Service (USA) 
(Watkins, Wright, 2007; Vv.Aa., 2004a; Vv.Aa., 2004b; Vv.Aa., 2004c; Vv.Aa., 2008b).

The Management Plan provides goals and strategies of intervention, aiming to the best conservation and valorization of the historic garden heritage, connecting maintenance, restoration and promotion actions.

The Management Plan, which approach is multidisciplinary, is elaborated taking into account also feasibility conditions (technical, regulatory, professional, cultural, ...), but is not impeded by the restrictions laid down by instant sustainability requirements, formulating instead a clear vision for the garden and providing a list of policies and actions aimed at solving - in the medium to long term - site specific issues and at enhancing its development.

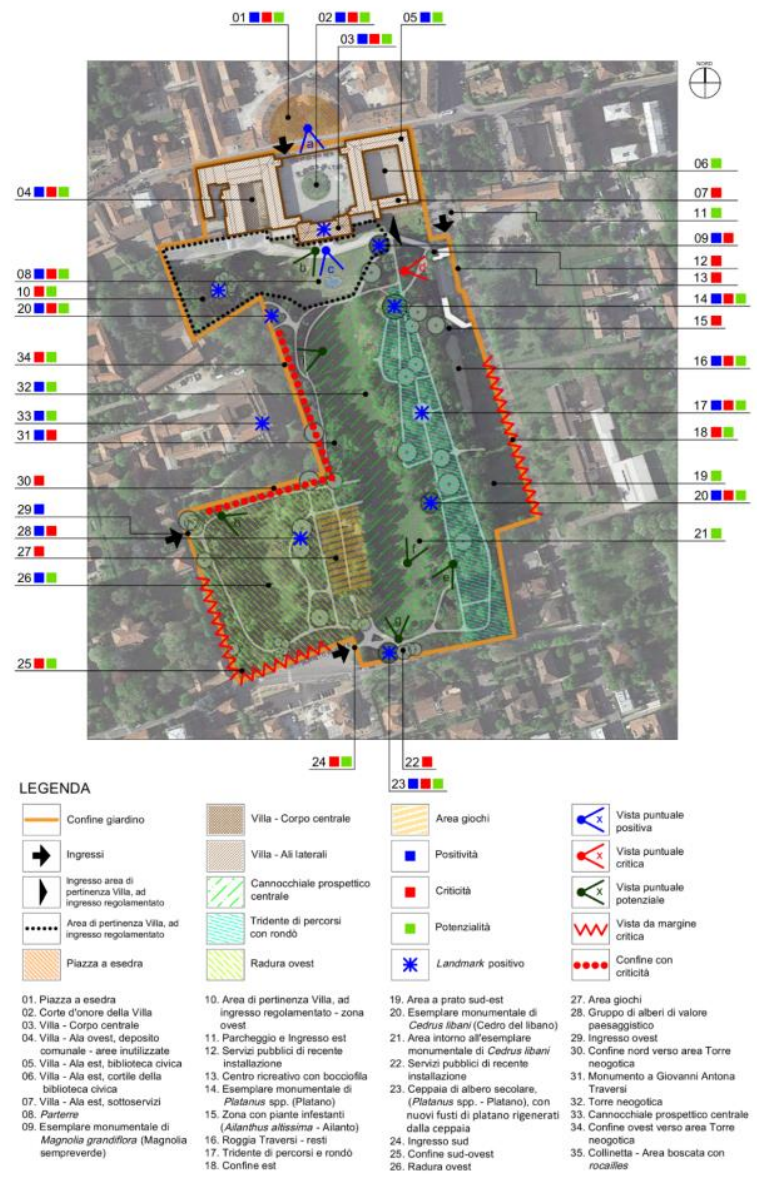

Figure 7. Plan of Villa Cusani Tittoni Traversi garden in Desio (Monza and Brianza Province), where elements and areas of special historic, architectural and botanic interest are shown, as well as the survey of decay, alteration and transformation issues, and site potentials. All these elements have to be considered to elaborate a Management Plan.

In order to define a Management Plan it is necessary to collect information about the site, detailing its history, settlement, architectural, natural and physical components, features, governance, type of users, current and wish conditions of uses and functions (Vv.Aa., 2001; Vv.Aa., 2008a) (Figure 7).

In particular, it is necessary:

- to understand the complexity of the historic public gardens;

- to recognize the cultural and botanic significance of historic public gardens, and also to consider them like a current urban, architectural, ecological, social resource;
- to analyze the constructive and material components and features of historical public gardens, to consider typologies and construction techniques, to understand the vegetation settlement, recognizing tree and shrub species and roles, to evaluate the level of decay, the connected climatic and microclimatic issues;

- to evaluate correct and wrong planting and management techniques;

- to select suitable species for specific planting sites, based on their ecological characteristics;

- to evaluate risk associated to urban trees;

- to define preservation and management strategies in order to control the transformations over time.

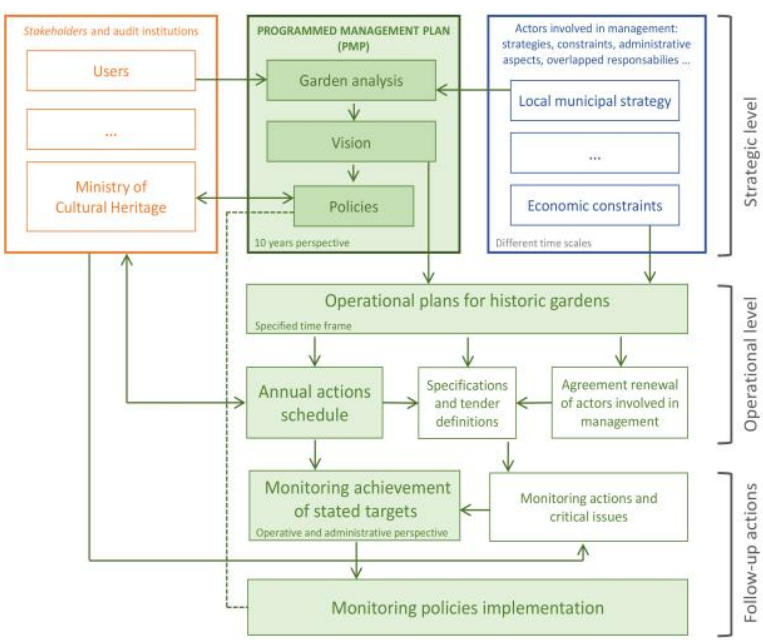

Figure 8. Flow chart of the decisional and operational aspects of the management of an historic garden.

Given absolute but realistic premises and a strategic vision, the first operational level must define operational targets, real goals to be achieved through the management of the asset, and feasible within a given timeframe.

Among these specific targets we can include:

- preserve historic garden peculiar features and history readability;

- enhance historic garden potentials, by proposing new activities and compatible uses;

- solve critical and existing issues;

- identify actions to be taken and prioritize interventions.

To facilitate the achievement of the operational targets, an annual planning can be done (Operational Plans), which will define timing and modalities of specific interventions execution, will take advantage of works specifications and any professional consultancy, and must provide appropriate communications to supervisory bodies (Ministry of Cultural Heritage, for example). The preparation of periodic reports (Monitoring Sheets) will be a valid way to monitor the achievement of the annual objectives, the overall operational objectives and the implementation of the management actions (Figure 8).

This general approach based on Management Plans and Operational Plans that document observations and decisions across all levels, from the strategic to the verification actions, allows to keep track of the management in a precise and practical way, and to transfer it also through changes in the political and administrative structures that can relate to the ownership and the managers of the property. 


\section{INFORMATION TECHNOLOGY TO MANAGE AND PROMOTE HISTORIC PUBLIC GARDENS}

Information Technology addresses the correct use of public gardens - particularly with historic and cultural value - also requires the development of new specific government and communication tools (planning tools at the municipal level: Green Plan, Green Regulation, Green Census, Management Plans), able to guide administrators in planning and management choices, but also providing citizens with elements of knowledge and respect for this important common heritage.

Information Technology's potential is rapidly increasing under different point of views: data, services, tools, hubs, applications. The growing availability of data access as in the case of Open Data and Geographic Open Data (GOD) - technical maps, specific thematic maps, multi-temporal satellite data, climate indicators, temperature data, raining data - help operators to scientifically support the analysis, planning and decision making. Open access to historical information for landscape analysis with the help of Spatial Data Infrastructure are demonstrating a potential capability to increase the perception of heritage values and its preservation (Brumana et al., 2013; Brumana et al., 2015). As in the case of the multimedia virtual museum of the Lake Como allowing tourists to virtually navigate across the past territories (Figure 9), and to use low cost cardboard to experiment the immersive reality potential in the fruition of the ancient vault passages of the lake landscape (Brumana et al., 2018).

Growing of infrastructures and data management services, from Spatial Data Infrastructure till the modern Virtual Hubs, act as intermediator among the multiplicity and fragmentation of open data sources shared by the Geoportals and services distributed by the different sources: regional bodies (technical regional maps updating, orthoimages, risk maps and geological maps, and many others), municipalities, national agencies (as the Agenzia del Territorio managing the current cadastral layer across Italy and the historic series of the last century and others series), and National Historical Archives conserving the historic map heritage, strategic to the historic garden analysis and knowledge. Moreover publication services technology are demonstrating that they can be useful for different analysis carried on correlating the historic map layers of a city for planning, built environment and transformation (Cuca at al., 2013) through the map registry using the current maps, and also for the inhabitants to understand their city over the centuries (Brumana et al., 2018).

The scarce connection among data limits the potential in their interconnection. Innovative technologies like Virtual Hubs have been introduced in the domain of large big data sets: Virtual Hubs are on developing, they are constantly improving instruments capable of discovering and accessing available and published open data without duplicating the data source. Virtual Hubs have been set up to Discovery and Access Brokering services, firstly applied to support Global Earth Observation (GEO-DAB), accessing satellite multi-temporal series integrated by other data for different purposes: climate change, health, water, air pollution, and others (Nativi et al., 2013).

Applications based on such Virtual Hubs have been recently implemented using the possibility to perform spatial temporal and semantic sub setting and queries. It is the case of GeoPAN Atla@s, an updatable customizable application that allows access to a set of multi-temporal geographical data and additional thematic layers to be used in professional environments, published as Open Data maps formats. The experimentation of brokering based gateway to geo-referenced historical and current maps for risk analysis demonstrated that the integration of different data sets can improve the knowledge of the territory at a granular level, involving different communities (Previtali, 2017). The application allows accessing more than 110 historical maps of seven European countries (Italy, France, Germany, Netherland, Spain, Belgium, United Kingdom) that have been crawled by advanced searcher. It can be updated by other historical data in the case of the historical gardens (Figures 10-11). The metadata information related to the maps (source, data of generation, scale) can be further implemented with other information coming from the GIS projects implemented in the case of the historic gardens (Cazzani et al., 2019).

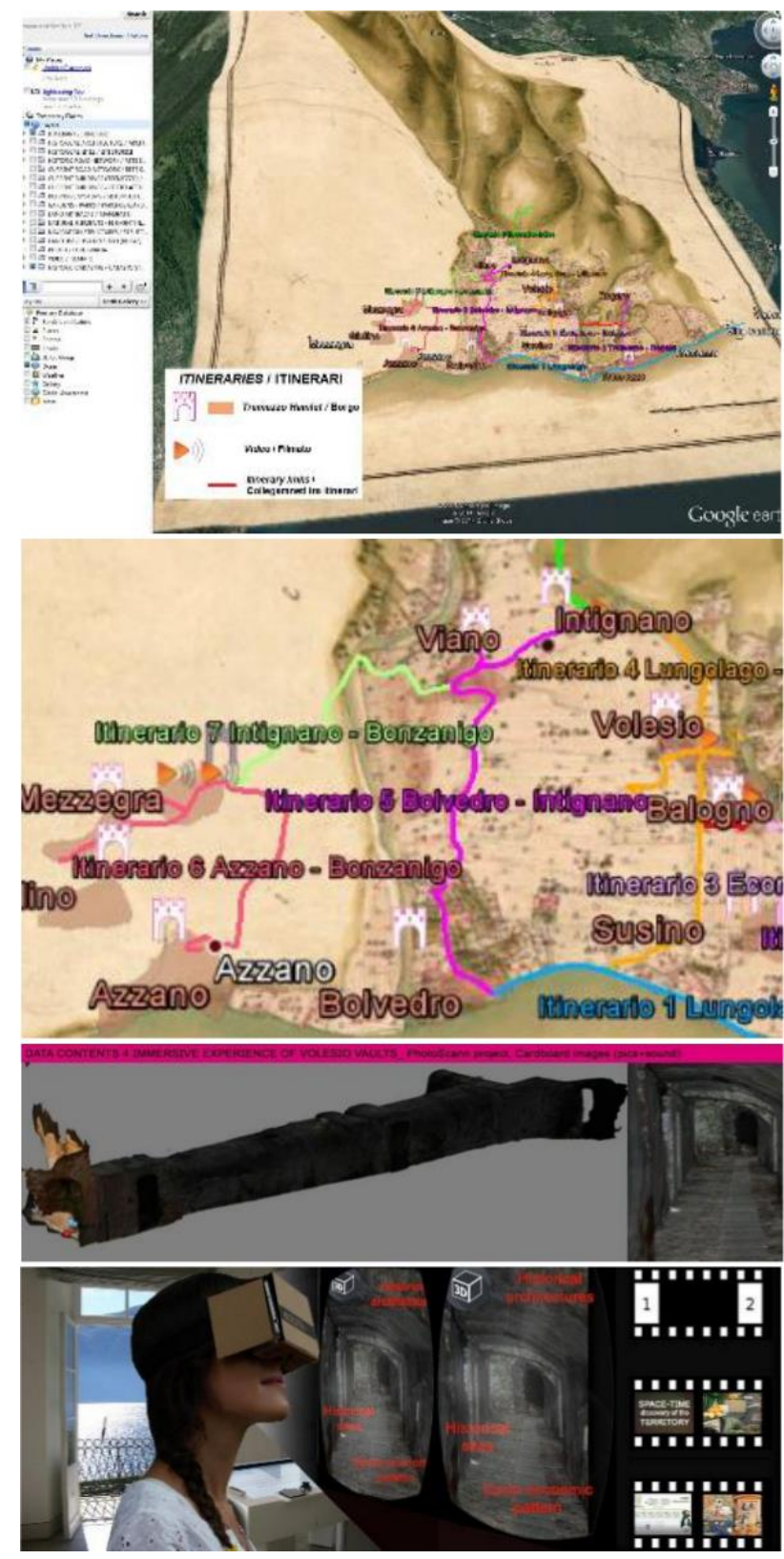

Figure 9. Low cost solution of panoramic photos\&cardboard fruition: the contents developed for an immersive experience of Tremezzina hamlets (above) starting from a WEBGIS (Volesio).

The visitors can choose among different thematic tours visualized on the different strips (in the centre). One of the immersive tour across the ancient passages in the Tremezzo hamlets (Como Lake) (bottom). 


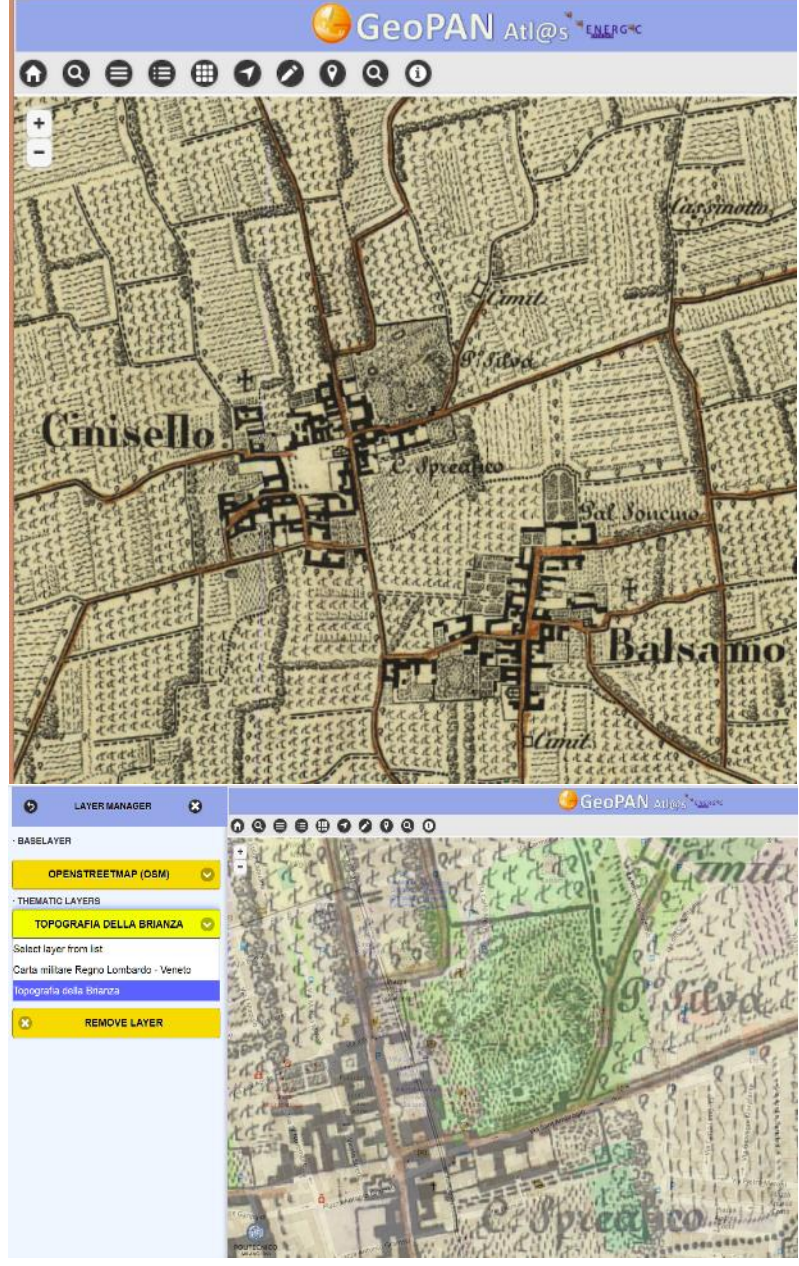

Figure 10. Villa Ghirlanda historic public garden in Cinisello Balsamo (Milan Province). The GEOPAN application allows users to query access and navigate the Brenna's map (Topografia della Brianza) georeferenced on the current map.

The use of WebGIS/GIS based tools in the historic garden domain, even better if open source to reduce costs and to spread the diffusion and access to their outputs, allows the creation of a georeferenced inventory and a detailed database, updatable in real time, even in the field, of all aspects concerning the management of trees and public parks, helping to optimize organizational and decision-making processes: special tools and software (including R3-Trees, GINVE, Arbomap, Tree App, Welcome 2 and MonumenTrees) to name a few are currently in use.

All the surveys and information regarding the urban green areas (limits of the managed areas, trees, bushes, lawns and flowerbeds, hedges, features, playgrounds and sports facilities) can be managed through the software, and their maintenance can be planned and documented. For example, among the types of data that can be entered and managed, we can list: the scientific survey and census of vegetation (georeferenced); the archive of survey results (VTA sheets, instrumental measurements, ...) carried out on each recorded tree; the possibility of planning phytopathological monitoring and actions based on risk classes; the scheduling of mowing, pruning, pesticide control and fertilization; and, in addition, the maintenance of features and the possibility of extracting statistical data, processing metric calculations for tenders, managing the reporting and closing the work carried out.
In this regard we can mention the interesting example of "Albera.TO", a web application, launched in 2017 and still under development, by the municipality of Turin (Italy), which allows the management and planning of all the green areas of the city, including historic parks and gardens. As far as the IT infrastructure is concerned, the Albera.TO database has been migrated from Oracle to PostGIS to allow data management in open-source mode. The new application allows the management of all data relating to the tree heritage by the municipal Green Service technicians. For the updating of the areas (locality) by the technicians, a configuration of the open-source software (QGIS) was created to allow the insertion of new geometries and the updating of existing ones. The geographical data entered or modified are updated in real time on the geographical level with the application, using a WFS-T protocol (international standard OGC interoperability). The data of plant and tree positions are updated on the Geoportal of the Municipality of Turin, where they can be consulted, interrogated and downloaded by the citizens.

The use of these types of IT tools should also help the preservation of the know-how and experience of the technical staff, because it makes the management information independent of a single operator, transferable from one element to another of the staff - if the Software licenses are continuously kept active and the staff is appropriately trained in the use of the programs - and accessible to all interested users, even with different authorization levels.

In the case of historic gardens, especially if they are public property, what makes these types of software interesting is the potential possibility of integrating information relating to history, stratification of construction phases, architectural, material and botanical features into the data archive, changes in use and management, all fundamental elements to be taken into consideration when planning extraordinary or ordinary maintenance operations on sites of historical, artistic and cultural value.

Finally, these types of software can become, besides operational tools, also instruments of promotion and dissemination. If well

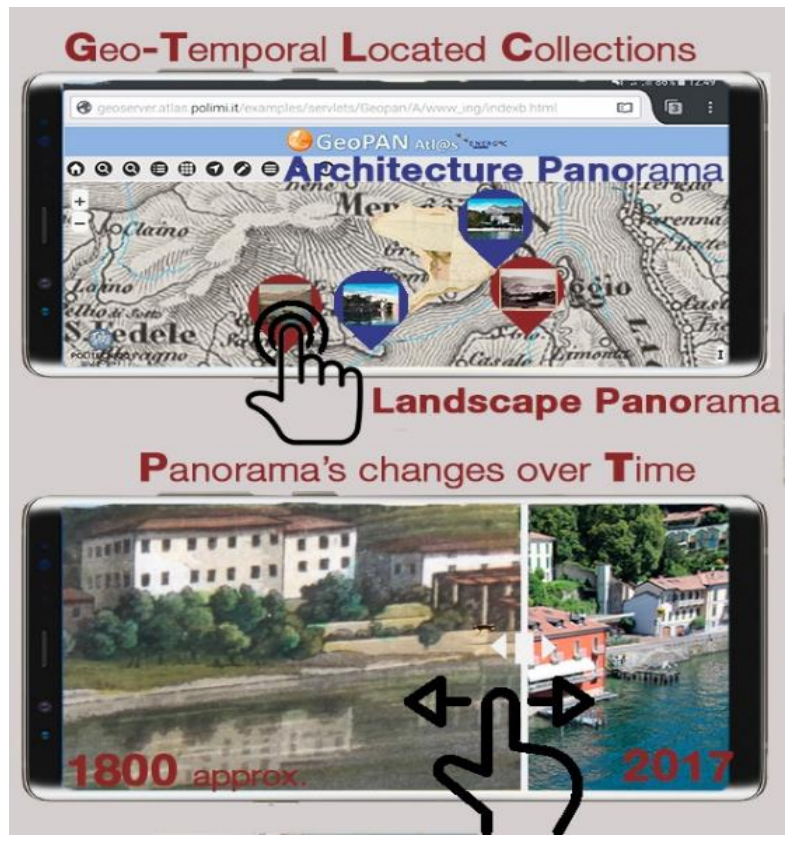

Figure 11. The GeoPAN APP can be customized to support virtual tour to better understand the past: landscape changes along Como Lake shore characterized by many historic gardens 
integrated with the public city web portal, and kept constantly updated, they can allow citizens to receive information on public parks in general and also to report any problems through mobile apps or dedicated web interfaces, increasing public involvement and encouraging respect for green spaces. Furthermore, considering also the potentialities of Augmented Reality, specific apps, by taking a picture of a simple target or QRcode, could enable everyone to discover the history of the place (Figure 11). They can be used to the botanical curiosities and the changes that the garden has undergone. For example, through the QRcode of a tree-stump, it might be possible to review the photograph of the plant before its abatement, or the display of historical photos or maps could help the visitor understand other different aspects of the garden, such as its changing relationship with the urban context. Since gardens in general, and the historic gardens in particular, are places in continuous and inevitable mutation, having a virtual reference to follow these transformations and rebuilt portions of the garden that changed considerably over time can be perceived, not only as an invaluable tool for experts who have to plan the conservation and management of the site, but also as a guide for the visitors and users who can be helped appreciate its complexity in the best way.

\section{CONCLUSIONS}

During the last decades many historic gardens, originally privately owned, became public and now appear transformed, simplified and in decay, due to poor maintenance and incompatible uses. As a result, there is often no easily readable distinction between historic gardens and ordinary urban green spaces. It is necessary to valorize this heritage, analyzing the complexity of historic public gardens and defining Management Plans in order to program adequate strategic governance. Information Technology not only efficiently collects and organizes data, but also educates and makes the public more aware of these valuable resources.

\section{ACKNOWLEDGEMENTS}

This paper collects the results of a Research Report elaborated by C.M. Zerbi, A. Cazzani, L.S. Pelissetti and L. Scazzosi in 2017-2018 and referring to the Research Project Appraise the heritage of historic gardens of Lombardy through the development of a sustainable network of expertise - The Programmed Management Plan as an operational tool, funded by Fondazione Cariplo in 2014-2016. The project partners included ReGiS - Rete dei Giardini Storici (Historical Gardens Network), Politecnico di Milano, Fondazione Minoprio, Scuola Agraria del Parco di Monza, the municipalities of Cinisello Balsamo, Desio, Gorgonzola, Lainate, Legnano, Merate and Sesto San Giovanni, and the Royal Park of Monza consortium. The research described here has been tested and developed within the Master in design and conservation of the garden and landscape offered by Politecnico di Milano and Fondazione Minoprio, that has been issued since 2003 and has involved over 200 students. Specifically plans attached here were elaborated in the Garden history and restoration course (Prof. Arch. A. Cazzani) by students M. Aspes, C. Zanzi and C.M. Zerbi for the Villa del Grumello historic garden case study, and by L. Bozzetti, M. Brevaglieri, A. Cavalli, V. Falanga, D. Figliuolo, L.G. Golzio, G. Karsioti, A. Ronzoni, N. Rossoni, F. Scarnecchia, M. Siri and M. Spanu for the Villa Cusani Tittoni Traversi historic public park case study.

\section{REFERENCES}

Boriani, M., Cazzani, A., 2004. Il difficile governo del giardino storico: molteplicità degli approcci conoscitivi e complessità della gestione degli interventi, in Brignani, M., Roncai, L., Giardini cremonesi, Del Miglio, Cremona, 49-63.

Brumana, R., Oreni, D., Cuca, B., Rampini, A., Pepe, M., 2013. Open access to historical information for landscape analysis in an SDI framework. International Journal of Agricultural and Environmental Information Systems (IJAEIS), 4(3), 18-40.

Brumana, R., Oreni, D., Caspani, S., Previtali, M., 2018. Virtual museums and built environment: narratives and immersive experience via multi-temporal geodata hub. Virtual Archaeology Review, 9(19), 34-49.

Cazzani, A., Brumana, R., Zerbi, C.M., 2019. The geo-referenced XIX century cartography: an analysis tool and a project reference for the preservation and management of built and landscape heritage. Int. Arch. Photogramm. Remote Sens. Spatial Inf. Sci., XLII-2/W11, 395-402.

Cuca, B., Brumana, R., Oreni, D., 2013. Geo-portals: more sustainable governance of territory within spatial data framework, in First International Conference on Remote Sensing and Geoinformation of the Environment (RSCy2013) (Vol. 8795) 87950G, International Society for Optics and Photonics.

Harney, M., 2014. Gardens and Landscapes in Historic Building Conservation, John Wiley \& Sons.

Mazzetti, P., Latre, M. Á., Ernst, J., Brumana, R., Brauman, S., Nativi, S., 2015. Virtual hubs for facilitating access to open data, in $E G U$ General Assembly Conference (Vol. 17).

Nativi, S., Craglia, M., Pearlman, J., 2013. Earth science infrastructures interoperability: the brokering approach. IEEE Journal of Selected Topics in Applied Earth Observations and Remote Sensing, 6(3), 11181129.

Previtali, M., 2017. Geopan atl@s: A brokering based gateway to georeferenced historical maps for risk analysis. International archives of the photogrammetry, remote sensing and spatial information sciences, 42(2W5), 583-589.

Previtali, M., Latre, M.Á., 2018. A brokered Virtual Hub approach for the generation of web applications based on historical maps, Appl Geomat 10(4), 453-472.

Watkins, J., Wright, T., 2007. The Management and Maintenance of Historic Parks, Gardens and Landscapes, The English Heritage.

Vv.Aa., 2001. Rooted in History - Studies in Garden Conservation, The National Trust Enterprises, London.

Vv.Aa., 2004a. A guide to producing Park and Green Space Management Plans, Cabe Space, London.

Vv.Aa., 2004b. 11 Modello del Piano di Gestione dei Beni Culturali iscritti alla lista del Patrimonio dell'Umanità - Linee Guida, Ministero per i Beni e le Attività Culturali, Commissione Nazionale Siti UNESCO e Sistemi Turistici Locali.

Vv.Aa., 2004c. Program standards - Park Planning, Associate Director, Park Planning, Facilities and Lands, National Park Service.

Vv.Aa., 2008a. Conservation Principles Policies and Guidance for the Sustainable Management of the Historic Environment, English Heritage.

Vv.Aa., 2008b. Preparing a Heritage Management Plan, Natural England. 